\title{
Three-dimensional distribution of water vapor estimated from tropospheric delay of GPS data in a mesoscale precipitation system of the Baiu front
}

\author{
Hiromu Seko $^{1}$, Seiichi Shimada ${ }^{2}$, Hajime Nakamura ${ }^{1}$, and Teruyuki Kato ${ }^{1}$ \\ ${ }^{1}$ Meteorological Research Institute, 1-1 Nagamine, Tsukuba, Ibaraki 305-0052, Japan \\ ${ }^{2}$ National Research Institute for Science Disaster Prevention Institute, 3-1 Tennodai, Tsukuba 305-0006, Ibaraki, Japan
}

(Received December 31, 1999; Revised July 26, 2000; Accepted September 7, 2000)

\begin{abstract}
Three-dimensional distributions of water vapor in a mesoscale precipitation system, which developed on 7 July 1996 in the Baiu front, were estimated directly from the GPS data of 'GPS Earth Observation Network' (GEONET) of the Geographical Survey Institute. In estimating the three-dimensional distribution of water vapor from the GPS data, we used the tropospheric delays along each path from GPS satellites to GPS receivers on the ground. The result showed that the moist air extended up to the height of $6 \mathrm{~km}$ in the precipitation region in the early stage of the precipitation system and that a dry air intruded into the precipitation system from the northwest in the middle-level (from $3 \mathrm{~km}$ to $5 \mathrm{~km}$ altitude) in the later stage. This dry air intrusion in the middle-level was supported by numerical simulations.
\end{abstract}

\section{Introduction}

In early summer, a quasi-stationary front, known as the Baiu front, is formed and extends from the China continent to the Japan Islands. In the Baiu front, mesoscale precipitation systems develop and cause heavy rainfalls and the flood disasters almost every year. Many special observations have been performed to investigate the structure and maintenance mechanisms of the precipitation systems. An important topic is the dry air intrusion in the middle-level into the precipitation systems (e.g. Ishihara et al., 1995). When dry air intrudes into the precipitation region, raindrops evaporate and the air temperature decreases. Cooling of the air in the middle-level leads to a more unstable atmosphere and an increase in convective activity. Therefore, the knowledge of the three-dimensional distribution of water vapor is indispensable for accurate forecasting of the mesoscale precipitation systems. However, we have so far a very coarse network of radiosonde soundings to observe water vapor fields in and around mesoscale precipitation systems.

Recently, a new observation method based on Global Positioning System (GPS) was developed. GPS receivers on the ground can continuously observe radio signals from GPS satellites. The phases of radio waves from GPS satellites are delayed by the atmosphere. These tropospheric delays consist of the hydrostatic and wet delays, which are proportional to surface pressure and precipitable water vapor (PWV), respectively. PWV can be thus calculated from the tropospheric delay, surface pressure and some assumption on temperature distribution. Fortunately for us, we can use the tropospheric delay data form a dense network, i.e. 'GPS Earth Observation Network (GEONET)’ of Geographical Survey

Copy right $(\mathrm{C}$ The Society of Geomagnetism and Earth, Planetary and Space Sciences (SGEPSS); The Seismological Society of Japan; The Volcanological Society of Japan; The Geodetic Society of Japan; The Japanese Society for Planetary Sciences.
Institute. The horizontal interval of GPS receivers in the network is $\sim 20 \mathrm{~km}$. We can obtain PWV data with the high spatial and temporal resolution.

However, since PWV is the vertical integrated water vapor, the vertical profile of water vapor is still unknown. In this paper, we show that using the tropospheric delays along the paths from GPS satellites to GPS receivers, the vertical profiles of the water vapor can be estimated by the least squares method.

In the following two sections, we discuss the structure of a mesoscale precipitation system in the Baiu front using the meteorological data and numerical simulations. In the Section 4, we discuss the GPS-derived PWV. In Sections 5 and 6 , a method to estimate the three-dimensional distributions of water vapor from GPS delay data is described. This method is applied to the mesoscale precipitation system in Section 7. Some discussions of the accuracy are also presented in Section 8. Summary is given in Section 9.

\section{Analysis Using Operational Meteorological Ob- servations}

The precipitation system of our interest developed near a low-pressure system in East-China Sea on 7 July 1996 (Fig. 1). The precipitation system was composed of several cloud regions I III. In the cloud region I, intense convective clouds developed in the warm sector of the low-pressure system. The stratiform clouds expanded northeastward form this convective cloud region. Another cloud region II developed near the center of the low-pressure system.

Figure 2 shows the rainfall intensity fields observed by conventional radar of Japan Meteorological Agency. Under the intense convective cloud region in I (Fig. 1), a line-shaped convective band (I in Fig. 2) stayed in the south of the Kyushu. Another precipitation area (II in Fig. 2) in the cloud region II (Fig. 1) moved eastward with a speed of $40 \mathrm{~km} /$ hour on 


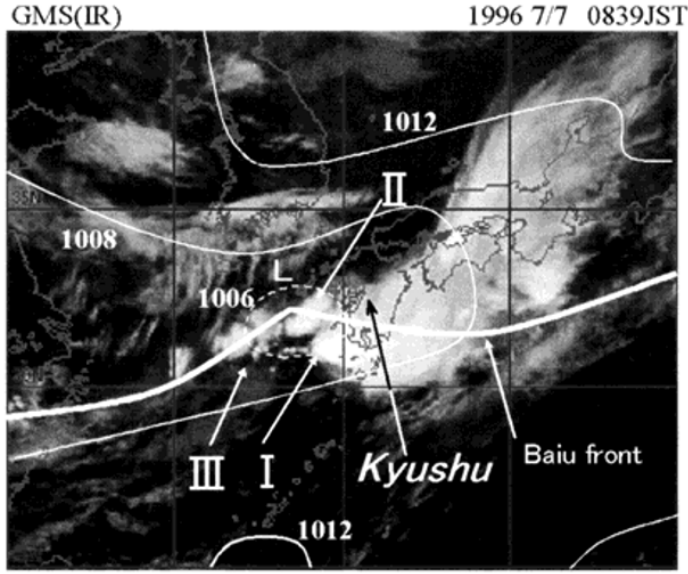

Fig. 1. Infrared image from GMS (Geostationary Meteorological Satellite) at 0839 JST 7 July 1996 and surface weather map at 0900 JST. Capital letter "L" indicates the position of the low-pressure system. "I", "II" and "III" denote cloud regions.
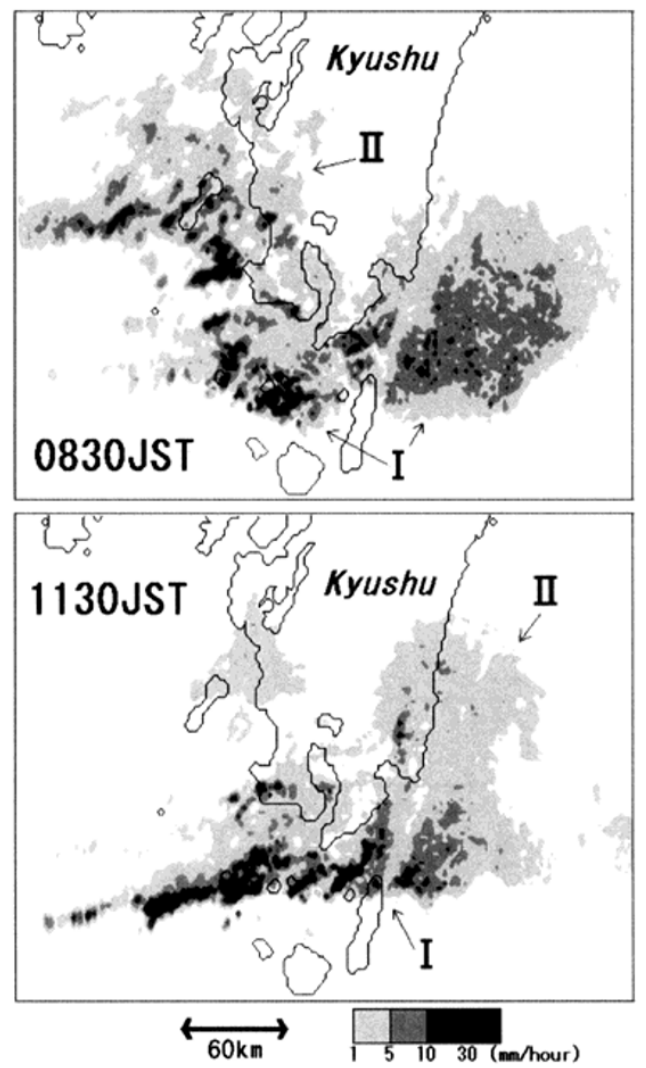

Fig. 2. Rainfall intensity fields at 0830 JST and 1130 JST 7 July 1996. Rainfall intensity was obtained from radar echo intensity data of Tanegashima radar of Japan Meteorological Agency. "I", "II" and "III" denote precipitation areas.

the northern side of the convective band I. The northern precipitation area II began to cross the Kyushu at 0830 Japan Standard Time (JST) and almost passed through it at 1130 JST. Thus, within only 3 hours, the eastern and western sides of the northern precipitation area II were observed over the Kyushu.
Vertical profiles of relative humidity, horizontal wind and equivalent potential temperature were analyzed from the operational radiosonde data at $0830 \mathrm{JST}$. In the precipitation area II, the moist air $(R H>80 \%)$ extended up to the height of $9.7 \mathrm{~km}$. The warm moist air in the low-level (below the height of $2 \mathrm{~km}$ ) to the south of the Baiu front was supplied into the precipitation system. The dry masses in the middlelevel were observed on the northern and southern sides of the Baiu front. As the operational radiosonde sites are roughly $300 \mathrm{~km}$ apart from each other and the time intervals of radiosonde soundings are 12 or 6 hours, the above results show only the large-scale fields in and around the Baiu front, which is larger than the mesoscale precipitation system of interest. These radiosonde soundings cannot resolve the mesoscale precipitation system. To investigate the atmospheric fields around the precipitation system, numerical simulations were performed.

\section{Numerical Simulations}

Numerical simulations were performed using the nonhydrostatic model of Meteorological Research Institute (MRI-NHM) (Saito, 1997). The horizontal grid spacing is $5 \mathrm{~km}$ to resolve the mesoscale precipitation system. The initial and boundary data were obtained by interpolating the forecast results of the operational forecast model (Regional Spectrum Model: grid spacing is about $20 \mathrm{~km}$ ) of Japan Meteorological Agency. The initial time of MRI-NHM is 0300 JST 7 July 1996.

As in the observation, a precipitation system developed over the southern Kyushu in the simulation (Fig. 3). The simulated precipitation system was composed of precipitation areas I III; an east-west-oriented convective band I, the eastward-moving precipitation area II on the north of the convective band I and the precipitation area III on the west of the convective band I. The shape and position of the precipitation system were similar to the observed one (see Fig. 2). At forecast time FT $=02 \mathrm{~h} 45 \mathrm{~m}$, which roughly corresponds 0830 JST in the observation, a dry air mass existed on the eastern side of the precipitation area II (Figs. 3(a) and 3(c)). At FT $=05 \mathrm{~h} 15 \mathrm{~m}$, which corresponds to $1130 \mathrm{JST}$ in the observation, the precipitation area II moved eastward and the dry air at middle-level $(z=2-4 \mathrm{~km})$ intruded into the convective band I and the precipitation area II from northwest and west (Figs. 3(b) and 3(d)).

\section{Horizontal Distribution of GPS-Derived PWV}

The horizontal distributions of hourly PWV were estimated from the GPS data of GEONET with Gamit software (King and Bock, 1999). We used GPS data observed with only Trimble receivers ( 32 points in Fig. 4). The elevation cut-off angle of $15^{\circ}$ and NMF mapping function (Niell, 1996) were used in the analysis. The procedure to estimate the PWV from the tropospheric delays is the same as that in Askne and Nordius (1987), Bevis et al. (1992) and Bevis et al. (1994).

The time-mean PWV from 0000 JST to 1800 JST 7 July 1996 indicates the large-scale horizontal distribution of water vapor as well as the influence of the altitudes of GPS receivers (Fig. 5(a)). The altitude of GPS receivers affects PWV, because PWV that observed by GPS receivers at high 


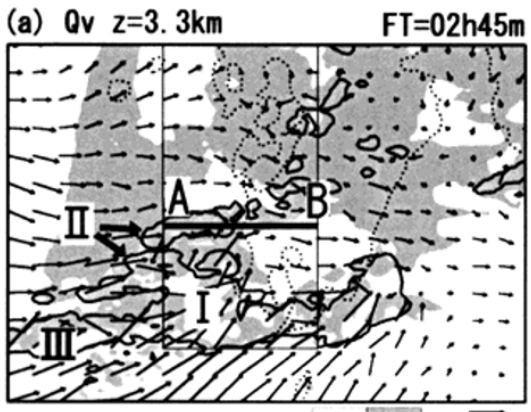

(c)

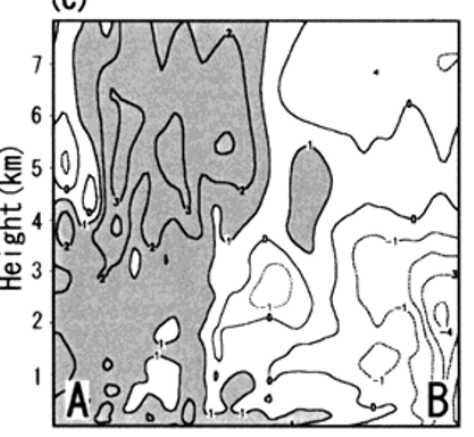

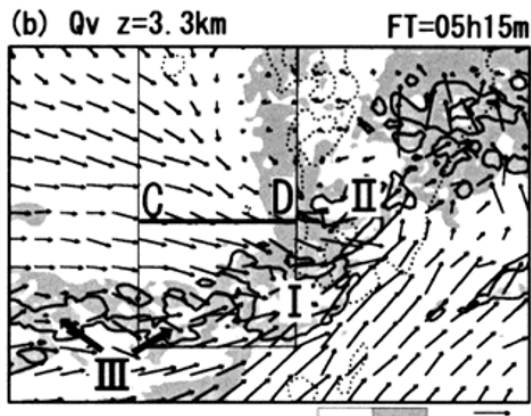

(d)

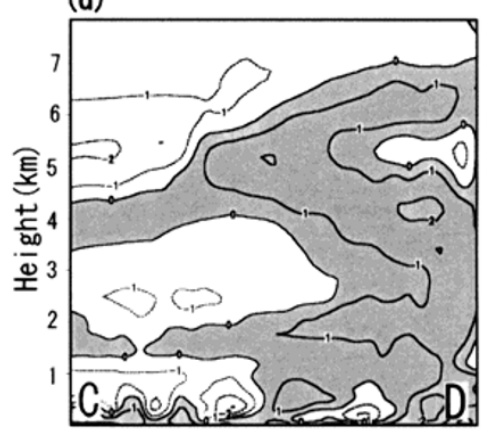

Fig. 3

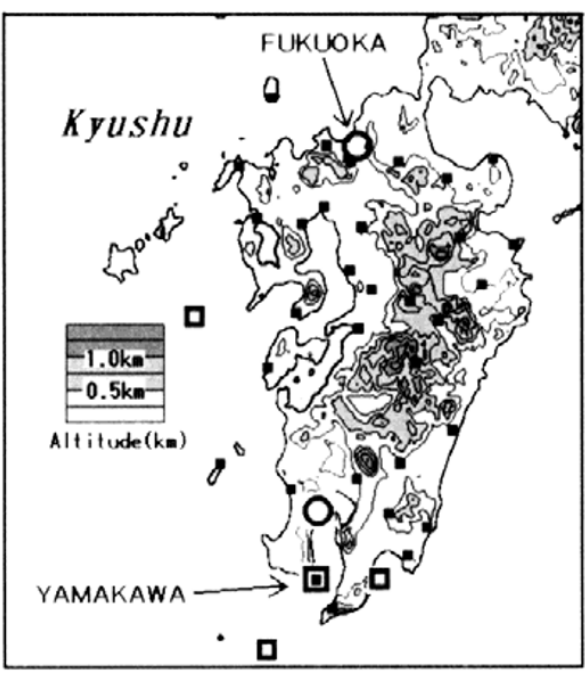

Fig. 4

Fig. 3. Horizontal distribution of specific humidity and horizontal wind at the height of $3.3 \mathrm{~km}$ and precipitation intensity at forecast time (a) FT $=02 \mathrm{~h}$ $45 \mathrm{~m}$ and (b) FT $=05 \mathrm{~h} 15 \mathrm{~m}$ and corresponding vertical cross sections of specific humidity deviation at (c) FT $=02 \mathrm{~h} 45 \mathrm{~m}$ and (d) FT $=05 \mathrm{~h} 15 \mathrm{~m}$. Precipitation intensity in (a) and (b) is calculated from the accumulated precipitation from FT $=02 \mathrm{~h} 30 \mathrm{~m}$ to FT $=02 \mathrm{~h} 45 \mathrm{~m}$ and from FT $=05 \mathrm{~h} 00 \mathrm{~m}$ to FT $=05 \mathrm{~h} 15 \mathrm{~m}$, respectively. In (a) and (b), shades indicate the regions with the specific humidity larger than $9 \mathrm{~g} / \mathrm{kg}$ and the areas enclosed by thick lines illustrate the rainfall intensity greater than $0.5 \mathrm{~mm} /$ hour. "I", "II" and "III" denote precipitation areas. In (c) and (d), specific humidity deviation is the difference along the line of A-B in (a) and along the line of C-D in (b) from the horizontal average over rectangle area surrounded by thin lines in (a) and (b), respectively.

Fig. 4. Locations of GPS receivers and topography of the Kyushu. Black squares indicate the GPS locations. Open circles and open squares indicate operational radiosonde sites and special experiment radiosonde sites, respectively.
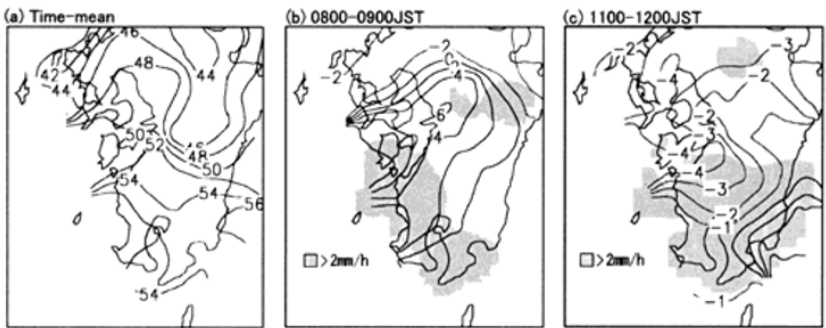

Fig. 5. Horizontal distributions of (a) the time-mean of precipitable water vapor (mm) from 0000 JST to 1800 JST on 7 July 1996 and the deviations from the time-mean (mm) at (b) 0800-0900 JST and (c) 1100-1200 JST. Shaded areas in (b) and (c) present the regions of hourly precipitation exceeding $2 \mathrm{~mm} / \mathrm{h}$. Hourly precipitation data was observed by Automated Meteorological Data Acquisition System operated by Japan Meteorological Agency.

altitude does not contain the water vapor under the altitude of GPS receivers. Thus, the deviations from the time-mean were used to indicate the temporal change of PWV due to the passage of the precipitation area II. When the precipitation area II began to cross the Kyushu at 0800-0900 JST from the west as shown by the hourly precipitation in Fig. 5, the deviation of hourly PWV was positive and large in the western Kyushu (Fig. 5(b)). When the precipitation area II almost passed through the Kyushu at 1100-1200 JST, the negative deviation of hourly PWV was observed on the northern and western sides of the precipitation area II (Fig. 5(c)). This negative region extended toward the precipitation band I. This suggests the dry air intrusion into the precipitation system. However, we cannot determine at which level the dry air intruded.

\section{Method of Estimating the Three-Dimensional Distribution of Water Vapor}

We evaluated three-dimensional distribution of water vapor from the tropospheric delays along each path from GPS satellites to GPS receivers using the following method (Fig. 6).

(1) The tropospheric delays along the paths from GPS satellites to GPS receivers are estimated with Gamit software. The tropospheric delays are converted into the water vapor amount along the path $\left(b^{p}\right)$. The superscript $p$ stands for the $p$-th path. This procedure is the same as the one in Section 4.

(2) The atmosphere over the analysis area is divided into regularly spaced boxes with an adequate size. It is assumed that the water vapor is uniform in each box with mean density $\left(x_{i j k}\right)$. The subscripts $i, j$ and $k$ indicate the location of the box in the $x, y$ and $z$ direction (Fig. 6(a)). 


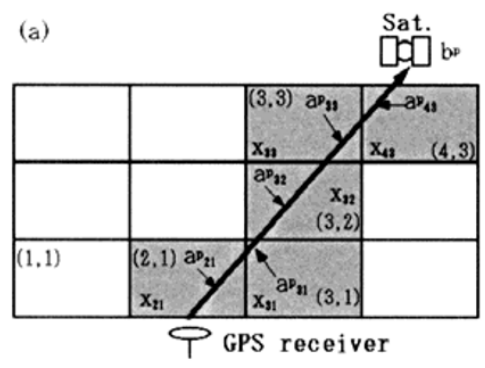

$a p_{21} x_{21}+a p_{11} x_{31}+a p_{22} x_{32}+a p_{31} x_{33}+a p_{43} x_{41}=b^{p}$.

(b)

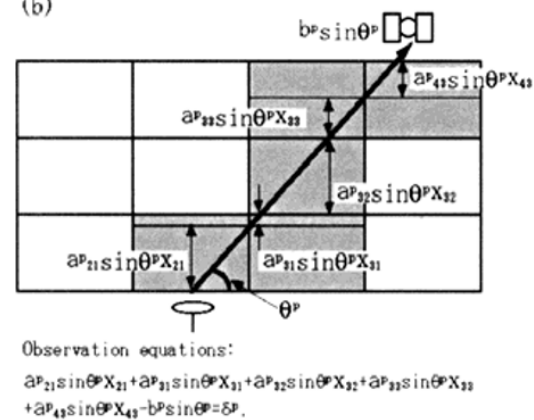

(c)

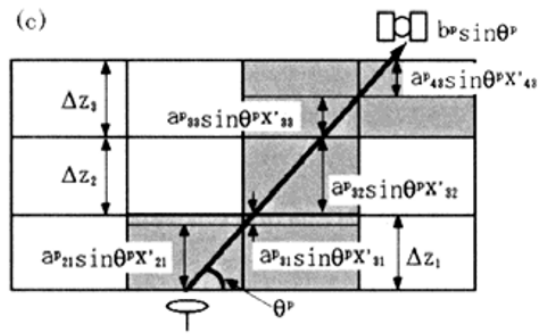

$\mathrm{X}^{\prime} \mathrm{ia}^{\mathrm{a}}=\mathrm{x}_{\mathrm{ik}}-\overline{\mathrm{X}}_{\mathrm{i}}$

$\Sigma_{j} a p_{i k} \sin \theta=\Delta z_{\mathbf{k}}$, for each layer $(k)$,

We assume $\Sigma_{\mathbf{x}} \bar{x}_{\mathbf{2}} \Delta \mathrm{z}_{\mathbf{l}}=\overline{\mathrm{P} W} \mathrm{~V}=\Sigma_{\mathrm{p}} \mathrm{b} \sin \theta / \mathrm{N}$.

Observation equations for the deviation:

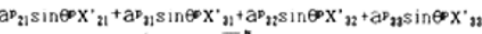

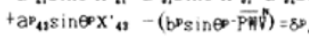

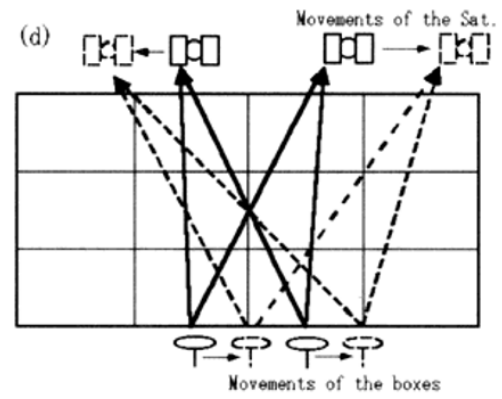

He move all boxes at the same speed of the precipitation system.

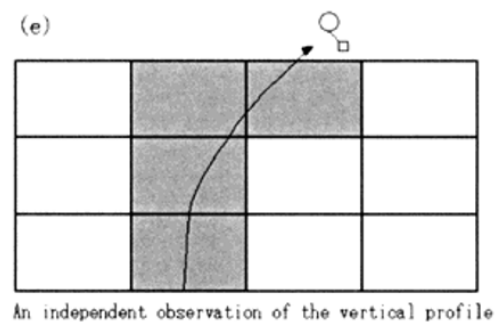

of the manter vapor density.

Fig. 6. Schematic illustration of the method of estimating the three-dimensional distribution of water vapor.
(3) The path lengths in each box $\left(a_{i j k}^{p}\right)$ are calculated along every path. Since water vapor density is water vapor amount per unit length, the integrated value of $a_{i j k}^{p}$ multiplied with the water vapor density in each box $\left(x_{i j k}\right)$ should be equal to observed water vapor amount $\left(b^{p}\right)$ for each path.

$$
\Sigma_{i j k}\left(a_{i j k}^{p} x_{i j k}\right)=b^{p}
$$

where

$$
a_{i j k}^{p}\left\{\begin{array}{c}
\neq 0, \text { when the path }(p) \\
\text { crosses the box }(i, j, k) \\
=0, \text { when the path }(p) \\
\text { does not cross the box }(i, j, k) .
\end{array}\right.
$$

The water vapor amount along the path $\left(b^{p}\right)$ depends on the elevation angle of the path $\left(\theta^{p}\right)$ (Fig. 6(b)). To remove the dependence of the elevation angle, Eq. (1) is multiplied with $\sim \theta^{p}$ so that all terms in Eq. (1) are mapped to the vertical direction.

$$
\Sigma_{i j k}\left(a_{i j k}^{p} \sin \theta^{p} x_{i j k}\right)=b^{p} \sin \theta^{p} .
$$

$a_{i j k}^{p} \sin \theta^{p}$ in Eq. (2) means the lengths of $a_{i j k}^{p}$ mapped to the vertical direction, $b^{p} \sin \theta^{p}$ is the water vapor amount mapped to the vertical directions. Here, we neglect the effects of the bending of the path and the curvature of the earth's surface.

The observed values of $b^{p}$ have an accidental error. Thus, the following observation equation for each path is constructed.

$$
\Sigma_{i j k}\left(a_{i j k}^{p} \sin \theta^{p} x_{i j k}\right)-b^{p} \sin \theta^{p}=\delta^{p} .
$$

In the observation equation, $a_{i j k}^{p} \sin \theta^{p}, x_{i j k}, b^{p} \sin \theta^{p}$ and $\delta^{p}$ are coefficients, unknowns, observed values and residuals, respectively.

(4) We divide the mean water vapor density in each box $\left(x_{i j k}\right)$ into the horizontal average in each layer $\left(\bar{x}_{k}\right)$ and the deviation form the horizontal average $\left(x_{i j k}^{\prime}\right)$ (Fig. 6(c)).

$$
x_{i j k}=x_{i j k}^{\prime}+\bar{x}_{k}
$$

where

$$
\Sigma_{i j} x_{i j k}^{\prime}=0 \text {. }
$$

Then the first term on the left-hand side of the Eq. (3) can be written as

$$
\begin{aligned}
\Sigma_{i j k}\left\{a_{i j k}^{p} \sin \theta^{p}\left(x_{i j k}^{\prime}+\bar{x}_{k}\right)\right\} \\
=\Sigma_{i j k}\left(a_{i j k}^{p} \sin \theta^{p} x_{i j k}^{\prime}\right) \\
\quad+\Sigma_{i j k}\left(a_{i j k}^{p} \sin \theta^{p} \bar{x}_{k}\right) \\
=\Sigma_{i j k}\left(a_{i j k}^{p} \sin \theta^{p} x_{i j k}^{\prime}\right) \\
\quad+\Sigma_{k}\left(\bar{x}_{k} \Sigma_{i j} a_{i j k}^{p} \sin \theta^{p}\right) .
\end{aligned}
$$

The horizontal sum of the vertical path length of each box $\left(\Sigma_{i j} a_{i j k}^{p} \sin \theta^{p}\right)$ at the layer $k$ is equal to the vertical thickness of the box $\left(\Delta z_{k}\right)$ at the layer $k$, so that

$$
\Sigma_{i j} a_{i j k}^{p} \sin \theta^{p}=\Delta z_{k} .
$$


Thus, Eq. (6) becomes

$$
\begin{aligned}
\Sigma_{i j k}\left\{a_{i j k}^{p} \sin \theta^{p}\left(x_{i j k}^{\prime}+\bar{x}_{k}\right)\right\}= & \Sigma_{i j k}\left(a_{i j k}^{p} \sin \theta^{p} x_{i j k}^{\prime}\right) \\
& +\Sigma_{k}\left(\bar{x}_{k} \Delta z_{k}\right)
\end{aligned}
$$

$\bar{x}_{k}$ appears only in the second term on the right-hand side of Eq. (8) as their vertical sum $\Sigma_{k}\left(\bar{x}_{k} \Delta z_{k}\right)$, which is common in all paths (i.e., all observation equations). Therefore, we cannot determine the individual $\bar{x}_{k}$ but only can the sum $\Sigma_{k}\left(\bar{x}_{k} \Delta z_{k}\right)$.

(5) The vertical sum of horizontal averaged water vapor density $\left(\Sigma_{k}\left(\bar{x}_{k} \Delta z_{k}\right)\right)$ corresponds to the horizontal average of PWV. PWV at each GPS receiver has been estimated using a conventional GPS analysis software, as stated above. However, here we assumed horizontal average of the PWV is equal to the mean of $b^{p} \sin \theta^{p}$ over all paths in the analysis area.

$$
\Sigma_{k}\left(\bar{x}_{k} \Delta z_{k}\right)=\overline{\mathrm{PWV}}^{N}=\Sigma_{p}\left(b^{p} \sin \theta^{p}\right) / N .
$$

where $N$ is the total number of the paths in the analysis area and $\Sigma_{p}$ means the summation over all paths. With the assumption (9) and Eq. (7), Eq. (3) is transformed into the following observation equation for the deviation $\left(x_{i j k}^{\prime}\right)$.

$$
\begin{aligned}
& \Sigma_{i j k}\left(a_{i j k}^{p} \sin \theta^{p} x_{i j k}^{\prime}\right) \\
& \quad-\left\{b^{p} \sin \theta^{p}-\overline{\mathrm{PWV}}^{N}\right\}=\delta^{p} .
\end{aligned}
$$

(6) When the interval of the GPS receivers is comparable to the size of the box, the path-crossed boxes are unevenly distributed in the analysis area; furthermore, the number of the paths for each GPS receivers is usually 5 to 6 , if the cut-off angle of $15^{\circ}$ is used. To make the distribution of the path-crossed boxes more impartial and increase the number of the paths, we moved all boxes with the same speed of the precipitation system for some adequate period. In doing so, the relative positions of each box to the precipitation system remain unchanged and the path lengths in each box $\left(a_{i j k}^{p}\right)$ change with time due to the movements of the boxes as well as the position changes of GPS satellites (Fig. 6). If it can be assumed that the precipitation system is quasi-stationary during this analysis period, we can use all observed data of $b^{p}$ in the analysis period.

(7) Finally, we will minimize the residuals with some constraints in a least square sense;

$$
\begin{gathered}
J=\Sigma_{p}\left\{\Sigma_{i j k}\left(a_{i j k}^{p} \sin \theta^{p} x_{i j k}^{\prime}\right)\right. \\
\left.-\left(b^{p} \sin \theta^{p}-\overline{\mathrm{PWV}}^{N}\right)\right\}^{2} \\
+\Sigma_{k} \lambda_{k}\left(\Sigma_{i j} x_{i j k}^{\prime}\right)+\Sigma_{i j k}\left(x_{i j k}^{\prime 2} / \sigma_{k}^{2}\right) .
\end{gathered}
$$

where $\lambda_{k}$ is the parameter of the Lagrange's method of indeterminate coefficients and $\sigma_{k}$ is standard deviation of water vapor density at layer $k$. Then we have the normal equation;

$$
\begin{aligned}
& \Sigma_{p} \Sigma_{i j k} a_{i j k}^{p} \sin \theta^{p}\left\{\Sigma_{i j k}\left(a_{i j k}^{p} \sin \theta^{p} x_{i j k}^{\prime}\right)\right. \\
& \left.-\left(b^{p} \sin \theta^{p}-\overline{\mathrm{PWV}}^{N}\right)\right\} \\
& +\Sigma_{i j k}\left(x_{i j k}^{\prime} / \sigma_{k}^{2}\right)=0, \quad \text { for each path }(p),
\end{aligned}
$$

with

$$
\Sigma_{i j} x_{i j k}^{\prime}=0 \quad \text { for each layer }(k) .
$$

Finally, we solved the linear simultaneous equation and obtained the most probable value of $x_{i j k}^{\prime}$.

(8) If another independent vertical profile of water vapor (e.g., the vertical profile observed by the radiosonde or the water vapor radiometer) is available in the analysis area, the horizontal averages of water vapor density $\left(\bar{x}_{k}\right)$ could be calculated from the vertical profile of the independent data and deviations obtained by this method $\left(x_{i j k}^{\prime}\right)$. Then, we could obtain the absolute values of water vapor density in whole analysis area (Fig. 6(e)).

\section{A Test of the Method with Actual Distribution of GPS Receivers and GPS Satellites}

To resolve the mesoscale precipitation system, the boxes with $17 \mathrm{~km} \times 17 \mathrm{~km} \times 1 \mathrm{~km}$ size and analysis periods of 1 hour (i.e., 0800-0900 JST and 1100-1200 JST) were used.

To make the assumption of $\Sigma_{k}\left(\bar{x}_{k} \Delta z_{k}\right)=\overline{\mathrm{PWV}}^{N}=$ $\Sigma_{p}\left(b^{p} \sin \theta^{p}\right) / N$ in Eq. (9) valid, we need a special treatment in the lowest layer because several GPS receivers are located at the high altitudes while $\Delta z_{k}$ is fixed to $1 \mathrm{~km}$ from sea level in the lowest layer. We extrapolated $b^{p} \sin \theta^{p}$ at each receiver to the sea level using the altitude of the GPS receiver $\left(z_{r}\right)$ and the representative value of the water vapor density $\left(x_{0}\right)$ in the lowest $100 \mathrm{~m}$ from the sea level, which was determined from operational radiosonde data and some more specially launched for this study during 0830 JST-1130 JST in this paper (positions of the radiosonde sites indicated in Fig. 4). We used GPS receivers only with the altitude less than $100 \mathrm{~m}$ for this extrapolation. Thus Eq. (9) is changed to;

$$
\begin{aligned}
\Sigma_{k}\left(\bar{x}_{k} \Delta z_{k}\right) & =\overline{\mathrm{PWV}}^{N} \\
& \left.=\Sigma_{p}\left\{\left(b^{p} \sin \theta^{p}\right)+x_{0} \times z_{r} / \Delta z_{l}\right)\right\}_{k} \\
& \quad\left(z_{r}<100 \mathrm{~m}\right),
\end{aligned}
$$

where $\Delta z_{1}=1000 \mathrm{~m}$.

The water vapor amount along the path $\left(b^{p}\right)$ is estimated every minute. Since $b^{p}$ has a high frequency fluctuation, the 5-minute average of $b^{p} \sin \theta^{p}$ is used.

The standard deviation of water vapor density $\left(\sigma_{k}\right)$ is determined from operational and special experiment radiosonde data during $0830 \mathrm{JST}-1130 \mathrm{JST}$. The following profile of $\sigma_{k}$ is used in this paper:

$$
\sigma_{k}= \begin{cases}1.15 \times 10^{-3} & (k=1,2, \ldots, 6), \\ 7.5 \times 10^{-4} & (k=7) \\ 3.5 \times 10^{-4} & (k=8)\end{cases}
$$

Before applying the proposed method to the observed GPS data, we tested the accuracy of the method using an artificial water vapor distribution shown in left panels of Fig. 7. We calculated artificial water vapor amounts along the paths from the artificial water vapor distribution and used them instead of the observed data for the analysis. The positions of GPS receivers and GPS satellites were the same as the observed ones. Since the estimated distributions varied according to the box position at the start time of the analysis 


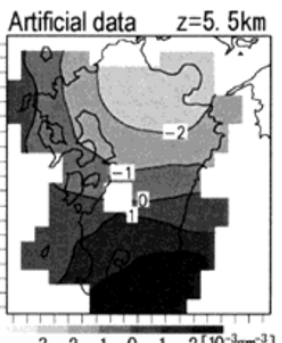

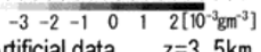

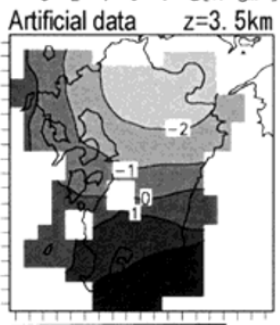

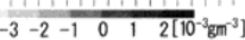

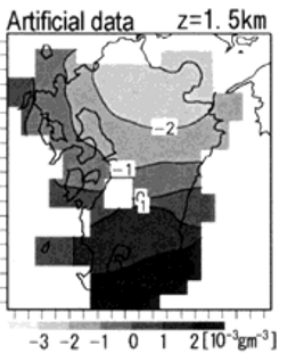

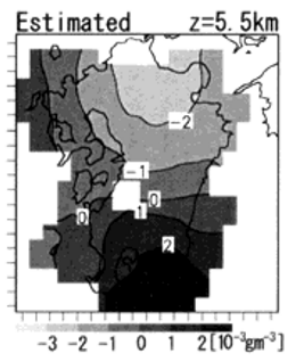
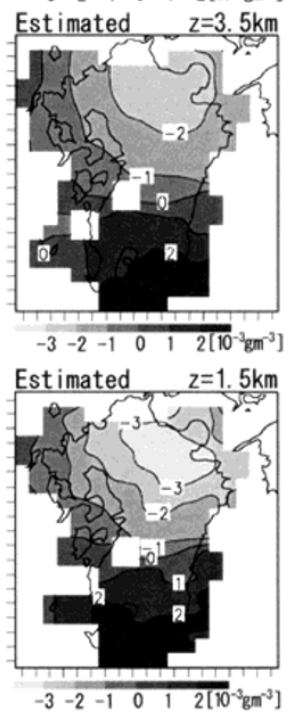

Fig. 7. Artificially given distribution of water vapor density (left) and estimated distribution using the proposed method (right). Ticks on the axes indicate the position of boxes.

period, four tests were performed by shifting the initial box position by the half size of the box in the $x$ and $y$ directions. That is, the boxes were shifted by $(0 \mathrm{~km}, 0 \mathrm{~km}),(8.5 \mathrm{~km}$, $0 \mathrm{~km}),(0 \mathrm{~km}, 8.5 \mathrm{~km})$ and $(8.5 \mathrm{~km}, 8.5 \mathrm{~km})$. From among four tests, we chose the best box position, with which the estimated deviations were most similar to the artificially given ones. Right panels of Fig. 7 show the estimated horizontal deviations with the best box position. The estimated horizontal deviations at middle levels $(z=3.5$ and $5.5 \mathrm{~km})$ were similar to the artificially given ones, although the estimated deviation at the height of $1.5 \mathrm{~km}$ was smaller in the northern Kyushu. This comparison illustrates that the method has sufficient accuracy in estimating the three dimensional distribution of water vapor. The best initial position of the boxes was used in the analysis of the observed GPS data.

\section{Three Dimensional Distribution of Water Vapor around the Precipitation System}

Figure 8 shows the deviations of water vapor density from horizontal average estimated from the observation. At 0800 0900 JST when the northern precipitation area II was observed over the southwestern Kyushu (see Fig. 2(a)), the moist air $\left(>10^{-3} \mathrm{gm}^{-3}\right)$ extended to the height of $6 \mathrm{~km}$ in the precipitation region (Fig. 8(a)). The dry air region existed on the eastern side of the precipitation region II. At 1100-1200 JST when the northern precipitation area II moved to the southeast of the Kyushu (see Fig. 2(b)), the relatively dry air $\left(<10^{-3} \mathrm{gm}^{-3}\right)$ region about the height of

(a) 0800-0900JST
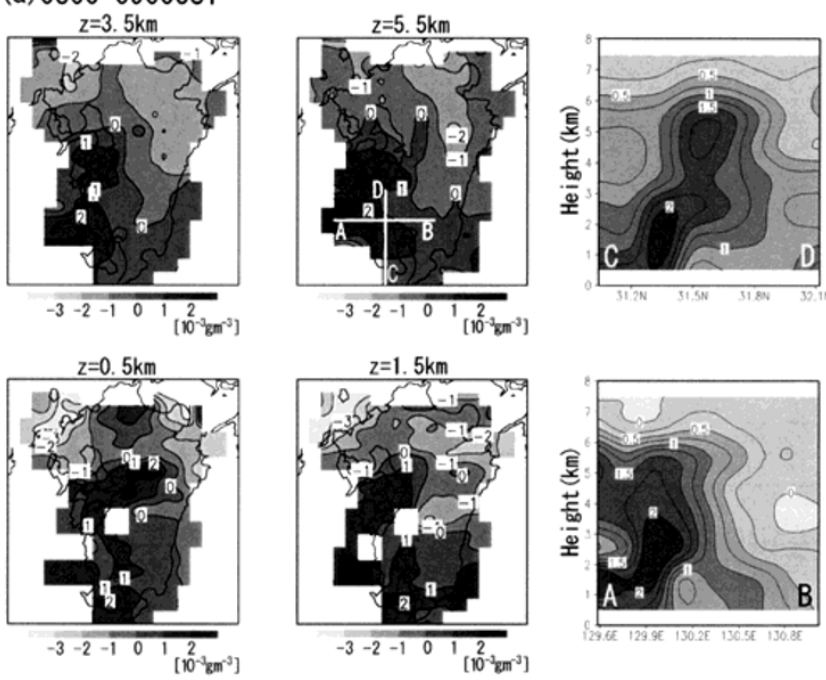

(b) 1100-1200JST
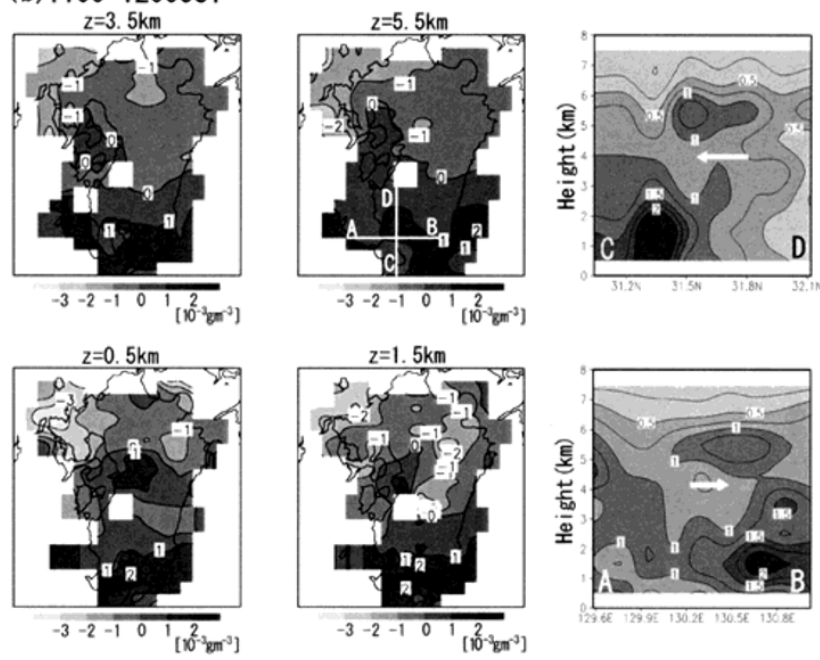

Fig. 8. Horizontal distributions and cross sections of the deviation of the water vapor density $\left(10^{-3} \mathrm{gm}^{-3}\right)$ at (a) 0800-0900 JST and (b) 1100-1200 JST. White lines in the panels of $z=5.5 \mathrm{~km}$ indicate the positions of cross sections. White arrows in the cross sections indicate dry air intrusion.

$4 \mathrm{~km}$ expanded southward (Fig. 8(b)). The dry air intrusion $\left(7.5 \times 10^{-4}-10^{-3} \mathrm{gm}^{-3}\right)$ into the precipitation system in the middle-level was also clearly shown by the cross sections at 1100-1200 JST. These distributions of the dry air are consistent with the simulated results (see Fig. 3), although the height of the dry air intrusion at the later stage is higher than the simulated one.

\section{Some Estimation of the Accuracy of the Method}

We evaluated the accuracy of the estimated water vapor distribution for the actual observation. Figure 9 shows the scatterplots of $\Sigma_{i j k}\left(a_{i j k}^{p} \sin \theta^{p} x_{i j k}^{\prime}\right)$ and $\left(b^{p} \sin \theta^{p}-\overline{\mathrm{PWV}}^{N}\right)$ for every path. In the test (i.e., artificial case), almost all points are on a line with inclination of $45^{\circ}$ and the root-meansquare (rms) of the differences between the two values is about $0.3 \mathrm{~mm}$. In the actual case, the rms of the differences is about 1.5-1.6 $\mathrm{mm}$ and five times as large as the one of the test case. In this method, we assumed that the three-dimensional 

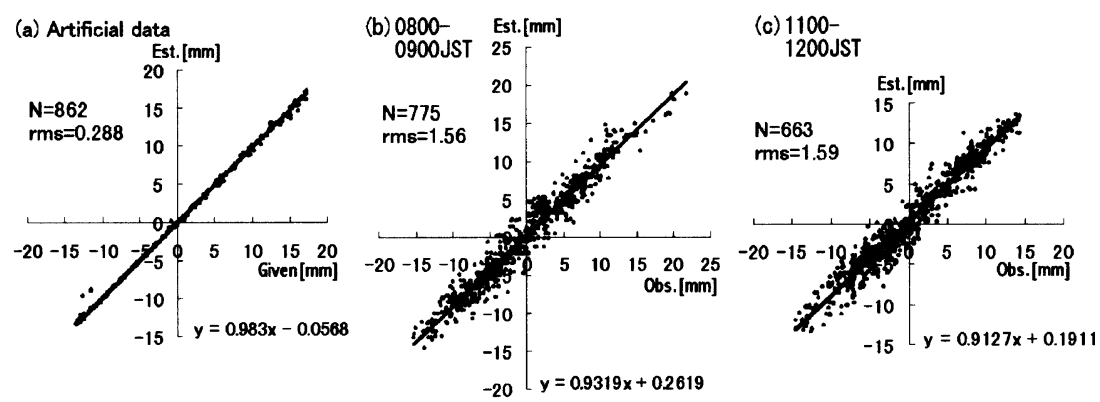

Fig. 9. Scatterplots of $\Sigma_{i j k}\left(a_{i j k}^{p} \sin \theta^{p} x_{i j k}^{\prime}\right)$ against the observed value of $\left(b^{p} \sin \theta^{p}-\overline{\mathrm{PWV}}^{N}\right)$.

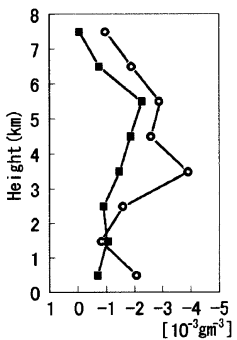

Fig. 10. Vertical profiles of the difference of water vapor density between Fukuoka and Yamakawa for GPS at 0800-0900 JST (black squares) and radiosonde at 0830 JST (open circles). Water vapor density from radiosonde soundings were averaged vertically every $1 \mathrm{~km}$ from sea level. Positions of Fukuoka and Yamakawa are indicated in Fig. 4.

distribution of water vapor density is quasi-stationary during the analysis period and uniform in each box. The test case, where these assumptions were rigorously satisfied in the artificial data, showed that the method could estimate the water vapor distribution accurately. Therefore, the large rms of the differences in the actual cases can be attributed to the inhomogeneity of the water vapor in the box and temporal changes of water vapor distribution.

Finally, the vertical profile of the difference of the estimated water vapor density was compared with the radiosonde data (Fig. 10). We used the difference between Fukuoka and Yamakawa radiosonde data at 0830 JST as a proof data. The difference of estimated water vapor density was calculated from the values at boxes corresponding to the two radiosonde sites (i.e., $(i, j)=(9,2)$ at Yamakawa and $(9,18)$ at Fukuoka). The horizontal difference of the GPS-estimated water vapor density coincides within $1.0 \times 10^{-3} \mathrm{gm}^{-3}$ except at $0.5 \mathrm{~km}, 3.5 \mathrm{~km}$ and $6.5 \mathrm{~km}$. The gap between GPS and radiosonde profiles at these heights was $1 \sim 2.5 \times 10^{-3} \mathrm{gm}^{-3}$ about half of the horizontal difference of water vapor density between the two radiosonde sites (see Fig. 8). The deviation of water vapor density estimated by the proposed method is the average value in the boxes during the 1 hour analysis period, while the radiosonde data is an instantaneous value at one point. These differences may cause the large gap in Fig. 10.

\section{Summary}

A method estimating the three-dimensional distribution of water vapor density from GPS data was developed and applied to the mesoscale precipitation system in the Baiu front.
At the early stage of the precipitation system, the moist air extended to the upper-level (above the height of $6 \mathrm{~km}$ ) in the precipitation region and the dry air region existed in the eastern side of the precipitation area. At the later stage, the dry air in the middle-level intruded into the precipitation system. These distributions of the water vapor are consistent with numerical simulation results. This fact and some error estimations encourage us to believe that our method is promising.

However there are some basic assumptions in this method, that is, uniform distribution of water vapor in each box and quasi-stationarity of the three-dimensional distribution of the water vapor during the analysis period. There were boxes through which only few paths cross. This would affect the accuracy of the estimation in those boxes. To evaluate the limitation due to these assumptions and to improve this method, further studies are needed.

Acknowledgments. The authors would like to thank anonymous referees, whose comments are very helpful to improve the manuscript. Thanks are extended to Geographical Survey Institute, Numerical Prediction Division of Japan Meteorological Agency and members of Torrential Rain Experiment for providing GPS data of GEONET, the initial and boundary data of the numerical simulation and radiosonde data of special experiment sites, respectively. This work is a part of 'GPS/MET Japan' project, which is financially supported by the Japanese Science and Technology Agency.

\section{References}

Askne, J. and H. Nordius, Estimation of tropospheric delay for microwaves from surface weather data, Radio Sci., 22, 379-386, 1987.

Bevis, M., S. Businger, T. A. Herring, C. Roken, R. A. Anthes, and R. H. Ware, GPS Meteorology: Remote sensing of the atmospheric water vapor using the Global Positioning System, J. Geophys. Res., 97, 15787-15801, 1992.

Bevis, M., S. Businger, S. Chiwell, T. A. Herring, R. A. Anthes, C. Roken, and R. H. Ware, Mapping zenith wet delay onto precipitable water, $J$. Appl. Meteor., 33, 379-386, 1994.

Ishihara, M., Y. Fujiyoshi, A. Tabata, H. Sakakibara, K. Akaeda, and H Okamura, Dual Doppler radar analysis of an intense mesoscale rainband generated along the Baiu front in 1988: Its kinematic structure and maintenance process, J. Meteor. Soc. Japan, 73, 139-163, 1995.

King, R. W. and Y. Bock, Documentation for the GAMIT GPS analysis software, Mass. Inst. Tech. and Scripps Inst. Oceanography, Dec. 1999.

Niell, A. E., Global mapping functions for the atmosphere delay at radio wavelengths, J. Geophys. Res., 101, 3227-3246, 1996.

Saito, K., Semi-implicit fully compressible version of the MRI mesoscale nonhydrostatic model-Forecast experiment of the 6 August 1993 Kagoshima Torrential Rain-, Geophys. Mag. Ser. 2, 2, 109-137, 1997.

H. Seko (e-mail: hseko@mri-jma.go.jp), S. Shimada, H. Nakamura, and T. Kato 